\title{
Community Based Prospective Study of Miscarriages in Context of Biomass Fuel Use by Tribal Women of Rural Remote Region
}

\author{
Shakuntala Chhabra ${ }^{1}$ and Vikas Rathod ${ }^{1}$ \\ ${ }^{1}$ Mahatma Gandhi Institute of Medical Sciences
}

October 2, 2021

\begin{abstract}
OBJECTIVE Community based prospective study was carried out to know about the occurrence of miscarriages in context of Biomass fuel use by rural tribal, pregnant women. DESIGN Cross-sectional analysis. SETTING Villages and Dr. Sushila Nayar Hospital, Utavali, Melghat, Amravati Maharashtra. POPULATION Study in 100 villages, all pregnancies included. METHODS After approval of the institute's ethics committee, study was conducted in 100 villages. After base information, villages were divided into 50 study, 50 controls, subdivided into 40 study villages with advocacy for protection from ill effects of Biomass fuel, 40 non-advocacy controls and 10 study villages where in addition to advocacy Chimneys were fixed on roofs of huts with no windows, for exit of smoke and 10 controls where neither advocacy was done nor Chimneys were fixed. MAIN OUTCOME MEASURES Change in occurrence of miscarriage with Biomass fuel use. RESULTS In 50 study villages, of 1005 pregnancies, $2.8 \%$ reported miscarriages and in 50 controls, of 1097 pregnancies $3.1 \%$ had miscarriage. Of 2700 pregnancies in 40 Advocacy study villages $6.6 \%$, of 40 controls of 2700 pregnancies, $10.5 \%$ had miscarriages. In 10 villages with Advocacy as well as Chimneys, of 700 pregnancies, $2.4 \%$ had miscarriages in 10 controls, of 700 pregnancies $5.6 \%$ ended in miscarriages. In first year it could have been underreporting. CONCLUSION In rural tribal women miscarriages were not more than globally known, but Biomass fuel did affect occurrence of miscarriages.
\end{abstract}

\section{Hosted file}

Miscarriages in rural tribal women.pdf available at https://authorea.com/users/317240/ articles/540134-community-based-prospective-study-of-miscarriages-in-context-of-biomassfuel-use-by-tribal-women-of-rural-remote-region 